\title{
Telesonography - the 5th dimension of ultrasound examination
}

\section{Background}

At the very beginning, ultrasound examination was the result of reception of the ultrasound wave return from one ultrasound wave emission: uni-dimensional mode M. A second step in the evolution of ultrasound technology was to extend to several waves received in the same time yielding bidimensional (2D) examinations. Years later, a third dimension was successfully developed: plain images were examined by the whole volume as tridimensional (3D) images. The impressive success of 3D examinations, especially in the obstetrical field, lead to the fourth dimension: visualization of 3D images in real-time (4D). In a short time, based on fast development of information and telecommunication technologies, ultrasound images were transferred remotely to distant locations, which may be considered as the 5 th dimension. All these evolutions were the result of a process based on needs fulfilled.

\section{Definition and history \\ $\nabla$}

Telemedicine was a term coined in the early '70s, which literally means "healing

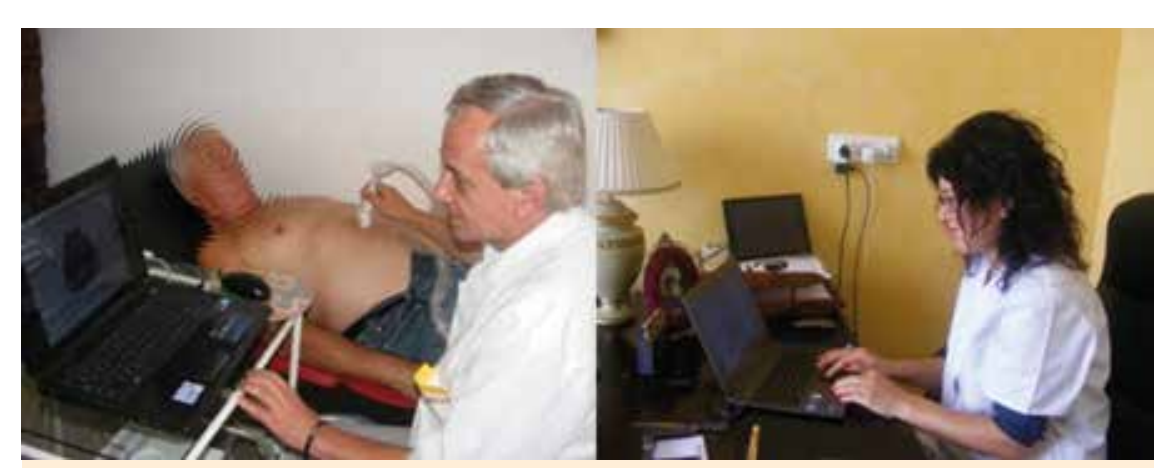

Conventional telemedicine session with an applicant seeing the patient and a remote telesonographer as the expert

at a distance", signifying the use of information and communications technologies (ICT) to improve patient outcomes by increasing access to healthcare and medical information [1].

In 1950, USA and Canada started to transmit radiological images and introduce a new notion: "telegnosis". During the same period (around 1954) the first medical application of ultrasound in medicine was also developed [2].Telesonography uses communications tools and applications to provide faster and improved ultrasonography examinations by receiving remote expert's opinion. Beginning of transmission for ultrasonography examinations via Internet was in the middle of the 9th decade of the twentieth century in Canada, Europe and Australia, in echocardiography and obstetrics [3-6].

\section{Telesonography structure $\nabla$}

Remote transmission of ultrasonography exams needs 3 components: an applicant with equipment and software (placed near the patient), an intranet or Internet connection, as well as a telesonographer with dedicated software for reading, asso- ciated or not with remote control capacities of examination [7].Telesonography usefulness has been demonstrated in veterinary medicine, also [8]. The importance and complexity of the subject has generated the need to synthesize the information in e-books [9].

Transmission at distance of ultrasound images can be achieved in 2 ways: storage and transmission versus real-time, with each variant having its own advantages and disadvantages. Store and forward process is simpler in 2 perspectives: it does not require synchronization of experts and does not require high and constant transmission speed. The disadvantage of sampling errors was exceeded in recent studies that have implemented such solutions, by storing 3D images whose interpretation facilitates the work of the experts [10]. Remote real-time transmission of ultrasonography runs in best conditions in high speed Internet connections with capabilities of remote control of images, although this does not seem to be a prerequisite [11].

Telesonography equipment includes dedicated systems or classic equipment with Internet transmission possibilities. Split components were developed recently: separate transducers adapted for mobile devices with specific software like smartphones, tablets, laptops, etc. [12-14]. Applicant categories include patients (emergencies, people from remote places, from 
sports, with disabilities, etc.), medical doctors (ultrasound-naïve doctors, trainees and residents, doctors without experience, specialists within other specialties, etc.), medical students, nurses, etc. A high speed network is preferred, either mobile (3G with maximum speed of $21 \mathrm{Mbps}, 4 \mathrm{G}$ with maximum speed of $100 \mathrm{Mbps}$, or satellite with maximum speed of $6 / 12$ Mbps) or fixed (ADSL with a maximum speed of $12 \mathrm{Mbps}$, ADSL 2 plus with a maximum speed of $24 \mathrm{Mbps}$ or even optical fibers with a maximum speed of 100 Mbps). Last, but not least, a specialist telesonographer with experience in ultrasonography has to assume the result of telesonography examination [15-16]

\section{Telesonography categories}

$\nabla$

Telesonographic projects have used, over the last 2 decades, one of 2 methods, depending on specific parameters, needs, possibilities and specialty features. Telesonography networks experimentally developed to follow the principle of "fulfillment of needs", were designed for assessment and monitoring of certain isolated communities or certain pathologies. Therefore, projects were carried out on the islands [17-18], on ships [19], on remote locations or even in space [20-22].

In terms of pathology concerned, the projects were implemented in the areas of emergency medicine, obstetrics and gynecology, cardiology, pediatrics, internal medicine branches and in primary care, etc. Few projects focused on the impact of telesonography in the educational process [23]. Hence, all projects have increased the chance of participants in accessing quality healthcare by reducing effort and time. Some projects evaluated functional parameters such as image quality [24-26], the social, financial and "quality-of-life" impact, developing various solutions to the needs identified: training lay persons in obtaining quality images [27] or developing robotic arms that are remotely guided by an expert to obtain high quality ultrasound images [28-30].

During earlier years of the "telesonography era", the performance equipment that could provide remote transmission of images had high prices, discrepant with income of the areas requiring wide access.
Development of the Internet and the availability of telecommuting programs (often offered freely on the Internet) have changed the situation and led to increased concerns for developing more accessible telesonography networks [31-35].

In the same time, a tendency to miniaturization for transducers and equipment (in order to make them more portable) has taken place.

Attaching versatile transducers at smartphones or tablets opens a new perspective for telesonography bringing the ultrasound transducer into the doctor's pocket, closer to the "old" stethoscope [12-14]. Recently, the term "echoscopy" has been coined to point out this evolution [36-37]. Nevertheless, the main problem that requires solving in the future is the availability of specialists in ultrasound by improving their working time and creating virtual collectives that provide state-of-theart services that will be increasingly demanded by telesonography.

\section{Clinical applications \\ $\nabla$}

\section{Emergency medicine}

In order to increase the efficiency of saving lives at risk in emergency situations, emergency medicine society has developed various protocols such as Focused Assessment with Sonography for Trauma (FAST). Through a short workout (20 minutes), paramedics were able to transmit ultrasound images interpretable in an average time of about 4 minutes, while the experts were able to provide an accurate assessment of the medical images and, consequently, to take corrective actions [38-39].

\section{Obstetrics and gynecology}

In this area the gap between the need for monitoring pregnancy or following-up chronic lesions, on the one hand, and the small number of specialists with an appropriate level of training, generated several projects of telesonography as compared to other areas. They used both the "store-and-forward" [40], as well as "realtime" technologies [41]. The examiner was being verbally guided remotely [42] or examination was performed using robotic arms [43]. In all cases the results were good, arguing for the necessity of implementation in other areas.

\section{Cardiology}

Echocardiography is particularly related to the speed of movement of heart valves during examination. For correct interpretation of the images a proper transmission speed for Internet or "store-and-forward" data is required, through usage of corresponding compression solutions [44]. A second feature is that examinations are limited and the placement and movement of the transducer influences the quality of the examination. In this field, a robotic arm was therefore used as a tool to increase picture quality [45].

\section{Pediatrics}

The same criteria were applied in examining children echocardiographs remotely, the result being even better, with a tremendous impact on the quality of life of young patients [46-47].

In conclusion, telemedicine achieved an impressive impact in recent years, while telesonography is definitely an area that will be developed in parallel due to the usefulness and increased availability associated with the downward trend in prices. The future looks bright and will certainly tell if this can be expanded to other diagnostic and therapeutic applications of clinical ultrasound.

\section{Carmen Daniela Nicolau}

Gastroenterology Department,

LotusLife Clinical Medical Center, Tirgu-

Mures, ROMANIA

References

1 .http://whqlibdoc.who.int/publications/2010/9789241564144_eng.pdf?ua=, cited on 15.11.2014.

2 Ryu S. Review of book: History of Telemedicine - evolution, context and transformation (Rashid L. Bashshur, Gary W Shannon, Department of Public Health and Healthcare Management, Inje Institute of Advanced Studies, Mary Ann Liebert, Inc.; 2009).Healthc Inform Res 2010;16(1):65-66.

3 Mendlowitz AD, Young DK.1. A system for full-motion real-time telesonography. AJR Am J Roentgenol 1992;159(5):1123-4.

4 Landwehr JB Jr, Zador IE, Wolfe HM, Dombrowski MP, Treadwell MC. Telemedicine and fetal ultrasonography: assessment of technical performance and clinical feasibility. Am J Obstet Gynecol 1997; 177(4): 846-8.

5 Johnson MA, Davis P, McEwan AJ, et al. Preliminary findings from a Telesonography study in Alberta. Telemed J 1998; 4:267-276.

6 Macedonia CR, Littlefield RJ, Coleman J, Satava RM, Cramer T, Mogel G, Eglinton G. Three-dimensional ultrasonographic telepresence. J Telemed Telecare 1998;4(4):224-30. 
7 Bassignani MJ, Dwyer SJ 3rd, Ciambotti JM, Olazagasti JM, Moran R, Moynihan S, Weaver $A C$, Snyder AM. Review of technology: planning for the development of telesonography.J Digit Imaging. 2004 Mar;17(1):18-27.

8 Papageorges M, Hebert P, Hanson J, Girard E, Leveille R, Feleciano J. Telesonography.Clin Tech Small Anim Pract. 2001 May; 16(2):11721.

9 Cavina E, Goletti O, Lippolis PV, Zocco G .Telesonography: Technical Problems, Solutions And Results In The Routine Utilization From Remote Areas ; IOS Press Ebooks ;DOI 10.3233/978-1-60750-925-7-88 Series

10 .Studies in Health Technology and Informatics; Ebook Volume 81: Medicine Meets Virtual Reality 2001

11 Macedonia CR, Littlefield RJ, Coleman J, Satava RM, Cramer T, Mogel G, Eglinton G. Three-dimensional ultrasonographic telepresence.] Telemed Telecare. 1998;4(4):224-30 Popov V, Popov D, Kacar I, Harris RD.The feasibility of real-time transmission of sonographic images from a remote location over low-bandwidth Internet links: a pilot study. AJR Am J Roentgenol. 2007 Mar;188(3):W219-22.

12 McBeth P, Crawford I, Tiruta C, Xiao Z, Zhu GQ Shuster M, Sewell L, Panebianco N, Lautner D, Nicolaou S, Ball CG, Blaivas M, Dente CJ, Wyrzykowski $A D$, Kirkpatrick $A W$. Help is in your pocket: the potential accuracy of smartphone- and laptop-based remotely guided resuscitative telesonography.Telemed J E Health. 2013 Dec;19(12):924-30.

13 Crawford I, Tiruta C, Kirkpatrick AW, Mitchelson $M$, Ferguson J.Big brother could actually help quite easily: telementored "just-intime" telesonography of the FAST over a smartphone.Ann Emerg Med. 2011 Sep;58(3):312-4.

14 McBeth PB, Hamilton T, Kirkpatrick AW. Costeffective remote iPhone-teathered telementored trauma telesonography.J Trauma. 2010 Dec;69(6):1597-9.

15 Sutherland JE, Sutphin D, Redican K, Rawlins $F$. Telesonography: foundations and future directions.J Ultrasound Med. 2011 Apr;30(4):517-22.

16 Bassignani MJ, Dwyer SJ 3rd, Ciambotti JM, Olazagasti JM, Moran R, Moynihan S, Weaver $A C$, Snyder AM. Review of technology: planning for the development of telesonography. J Digit Imaging. 2004 Mar;17(1):18-27

17 Balestri R1, Cavina E, Aliferis A, Goletti O, Rocci R, Lippolis PV, Zocco G, Franceschi M, Cotrozzi A, Economou S, Christofidis E. Telemedicine on a small island. J Telemed Telecare. 1999;5, Suppl 1:S50-2.

18 Zocco G, Goletti O, Lippolis PV, Lorenzetti L, Musco B, Cavina E, Tsolakidis K.TIMTEM project: our experience in a remote area.Telemed J E Health. 2003 Spring;9(1):117-21.

19 Nikolić N, Mozetić V, Modrcin B, Jaksić S. Might telesonography be a new useful diagnostic tool aboard merchant ships? A pilot study.Int Marit Health. 2006;57(1-4):198207

20 Law J, Macbeth PB. Ultrasound: from Earth to space.Mcgill J Med. 2011 Jun;13(2):59.
21 Vieyres P, Poisson G, Courreges F, Merigeaux $O$, Arbeille $P$. The TERESA project: from space research to ground tele-echography.Ind Rob. 2003;30(1):77-82

22 Martin DS, South DA, Garcia KM, Arbeille P. Ultrasound in space.Ultrasound Med Biol. 2003 Jan;29(1):1-12. Review.

23 Zocco G, Goletti O, Lippolis PV, et al. TIMTEM project: our experience in a remote area. Telemed J E Health 2003; 9:117-121.

24 .Quality assessments studies of tele ultrasonography ConfProc IEEE Eng Med Biol Soc. 2008;2008:5346-9

25 Istepanian RH, Philip N, Martini MG, Amso N, ShorvonP. Subjective and objective quality assessment in wireless teleultrasonography imaging.ConfProc IEEE Eng Med Biol Soc. 2008;2008:5346-9. doi: 10.1109/ IEMBS.2008.4650422

26 Burgul R, Gilbert FJ, Undrill PE. Methods of measurement of image quality in telesonography. Br J Radiol 2000; 73:1306-1312

27 Sheehan FH1, Ricci MA, Murtagh C, Clark H, Bolson EL. Expert visual guidance of ultrasound for telemedicine. J Telemed Telecare. 2010;16(2):77-82. doi: 10.1258/ jtt.2009.090313. Epub 2010 Feb 5.

28 Bruyère F, Ayoub J, Arbeille P. Use of a telerobotic arm to perform ultrasound guidance during renal biopsy in transplant recipients: a preliminary study.J Endourol. 2011 Feb;25(2):231-4. doi: 10.1089/ end.2010.0287. Epub 2010 Nov

29 Arbeille P, Capri A, Ayoub J, Kieffer V, Georgescu $M$, Poisson G. Use of a robotic arm to perform remote abdominal telesonography.AJR AmJRoentgenol.2007 Apr;188(4):W317-22.

30 Ito K, Sugano S, Takeuchi R, Nakamura K, Iwata $\mathrm{H}$. Usability and performance of a wearable tele-echography robot for focused assessment of trauma using sonography.Med Eng Phys. 2013 Feb;35(2):165-71.

31 Popov V1, Popov D, Kacar I, Harris RD. The feasibility of real-time transmission of sonographic images from a remote location over low-bandwidth Internet links: a pilot study.

32 Paulus YM, Thompson NP. Inexpensive, realtime tele-ultrasound using a commercial, web-based video streaming device.J Telemed Telecare. 2012 Jun;18(4):185-8.

33 Adambounou K, Adjenou V, Salam AP, Farin F, N'Dakena KG, Gbeassor M, Arbeille P. A lowcost tele-imaging platform for developing countries.Front Public Health. 2014 Sep $5 ; 2: 135$

34 Crawford I1, McBeth PB, Mitchelson M, Ferguson J, Tiruta C, Kirkpatrick AW. How to setup a lowcosttele-ultrasound capable videoconferencing system with wide applicability Crit Ultrasound J. 2012 May 29;4(1):13.

35 Pian L, Gillman LM, McBeth PB, Xiao Z, Ball CG, Blaivas M, Hamilton DR, Kirkpatrick AW. Potential Use of Remote Telesonography as a Transformational Technology in Underresourced and/or Remote Settings.Emerg Med Int. 2013;2013:986160

36 Barreiros AP, Cui XW, Ignee A, De Molo C, Pirri C, Dietrich $C F$. Echoscopy in scanning abdominal diseases: initial clinical experience. Z Gastroenterol. 2014 Mar;52(3):269-75.
37 Biais M, Carrié C, Delaunay F, Morel N, Revel $P$, Janvier G. Evaluation of a new pocket echoscopic device for focused cardiac ultrasonography in an emergency setting. Crit Care. 2012 May 14;16(3):R82.

38 Boniface KS, Shokoohi H, Smith ER, Scantlebury $K$. Tele-ultrasound and paramedics: realtime remote physician guidance of the Focused Assessment With Sonography for Trauma examination. Department of Emergency Medicine, George Washington University Medical Center, Washington, DC 20037, USA. kboniface@mfa.gwu.eduScand Surg. 2007;96(4):281-9.

39 Latifi R1, Weinstein RS, Porter JM, Ziemba M, Judkins $D$, Ridings $D$, Nassi $R$, Valenzuela $T$, Holcomb M, Leyva F. Telemedicine and telepresence for trauma and emergency care management.Am J Emerg Med. 2011 Jun;29(5):477-81. doi: 10.1016/j. ajem.2009.12.001. Epub 2010 Apr 13.

40 Arbeille P1, Fornage B, Boucher A, RuizJ, Georgescu M, Blouin J, Cristea J, Carles G, Farin F, Vincent $N$. Telesonography: virtual 3D image processing of remotely acquired abdominal, vascular, and fetal sonograms. J Clin Ultrasound. $2014 \mathrm{Feb}$;42(2):67-73.

41 Chan FY, Soong B, Lessing $K$, et al. Clinical value of real-time tertiary fetal Ultrasound consultation by telemedicine: preliminary evaluation. Telemed J 2000; 6:237-242.

42 Landwehr JB Jr, Zador IE, Wolfe HM, Dombrowski MP, Treadwell MC. Telemedicine and fetal ultrasonography: assessment of technical performance and clinical feasibility.Am J Obstet Gynecol. 1997 Oct;177(4):846-8.

43 Arbeille P, Ruiz J, Herve P, Chevillot M, Poisson $G$, Perrotin F. Fetal tele-echography using a roboticarm and a satellite link. Ultrasound Obstet Gynecol. 2005 Sep;26(3):221-6.

44 Barbier P, Dalla Vecchia L, Mirra G, Di Marco $S$, Cavoretto $D$. Near real-time echocardiography teleconsultation using low bandwidth and MPEG-4 compression: feasibility, image adequacy and clinical implications. J Telemed Telecare. 2012 Jun;18(4):204-10.

45 Arbeille P, Provost R, Zuj K, Dimouro D, Georgescu $M$. Teles-operated echocardiography using a robotic arm and an internet connection.Ultrasound Med Biol. 2014 Oct;40(10):2521-9.

46 Woodson KE, Sable CA, Cross RR, Pearson GD, Martin GR. Forward and store telemedicine using Motion Pictures Expert Group: a novel approach to pediatric teleechocardiography.J Am Soc Echocardiogr. 2004 Nov; 17(11):1197-200

47 Widmer S, Ghisla R, Ramelli GP, Taminelli F, Widmer B, Caoduro L, Gallino A. Tele-echocardiography in paediatrics.Eur J Pediatr. 2003 Apr;162(4):271-5. Epub 2003 Feb 25.

48 Mehta AR, Wakefield DS, Kienzle MG, Scholz $T D$. Pediatric tele-echocardiography: evaluation of transmission modalities.Telemed JE Health. 2001 Spring;7(1):17-25. 